\title{
The Enigmatic COVID-19 Vulnerabilities and the Invaluable Artificial Intelligence (Al)
}

\author{
Bongs Lainjo \\ Cybermatic International, Montréal, QC, \\ Canada
}

\begin{abstract}
The objective of the study is to conduct an exploratory review of the Covid-19 pandemic by focusing on the theme of Covid-19 pandemic morbidity and mortality, considering the dynamics of artificial intelligence and quality of life (QOL). The methods used in this research paper include a review of literature, anecdotal evidence, and reports on the morbidity of COVID-19, including the scope of its devastating effects in different countries such as the US, Africa, UK, China, and Brazil, among others. The findings of this study suggested that the devastating effects of the coronavirus are felt across different vulnerable populations. These include the elderly, front-line workers, marginalized communities, visible minorities, and more. The challenge in Africa is especially daunting because of inadequate infrastructure, and financial and human resources, among others. Besides, AI technology is being successfully used by scientists to enhance the development process of vaccines and drugs. However, its usage in other stages of the pandemic has not been adequately explored. Ultimately, it has been concluded that the effects of the Covid-19 are producing unprecedented and catastrophic outcomes in many countries. With a few exceptions, the common and current intervention approach is driven by many factors, including the compilation of relevant reliable and compelling data sets. On a positive note, the compelling trailblazing and catalytic contributions of AI towards the rapid discovery of COVID-19 vaccines are a good indication of future technological innovations and their effectiveness.
\end{abstract}

Keywords: Covid-19, quality of life, strategies, lessons learned, artificial intelligence

\section{Introduction}

History has a way of reminding us that while the good times are great, a business as usual comes with many unforeseen risks and challenges. On a positive note, stress, anxiety, and other mental health issues have turned around many mindsets in certain groups. There are now significant and unprecedented levels of compassion, empathy, and more, originating from many populations. One such instance, wherein significant challenges were posed to the community is at the time of the First World War. Besides, there was the Spanish plague, there was the second world war and for the last 60 plus years, we have had to live in a world of misgivings; ranging from populism to political unrests and instability in several parts of the world, primarily the Middle East and some parts of Asia.

When the current Coronavirus disease 2019 (COVID-19) started in December 2019, many assumed that like its predecessors H1N1, SARS, different plagues, and viruses, etc., it was going to pass with a thud (Chatterjee et al 2020: para 9). ${ }^{1}$ Five months into the pandemic and countries continue to live in fear, driven by many unknowns and limited scientific evidence. In the meantime, this
Correspondence: Bongs Lainjo

Email bsuiru@icloud.com 
aggressive, stealth, and brutal virus continues to spiral unabated. There is at least some consensus that once the peak of the pandemic has been achieved, there will be a reason for optimism. This is based on the assumption that everything being equal (continuous self-exclusion, personal hygiene, social distancing, etc.), the worst would then be behind us. For the most part, this assumption is correct if the processes are effectively and comprehensively implemented. The reality is that the potential for a subsequent wave is real and compelling. To be specific, as per the study findings of Salyer et $\mathrm{al}^{2}{ }^{2}$ the second wave of Covid-19, which was evident by December 2020, was more aggressive than the first one in several cases. In this regard, the Spanish flu, also known as the 1918 flu pandemic, serves as a classical example. Its second wave of infection proved to be even deadlier than the first after non-medical intervention measures put in place at the time had been relaxed. ${ }^{3}$

It must also be noted that during the outburst of COVID-19 also known as SARS-CoV-2 disease, healthcare workers are found to play a pivotal role. According to the report published by World Health Organization (WHO), ${ }^{4}$ healthcare workers have been providing frontline services in the pandemic. They are also found to undertake several responsibilities in maintaining health and wellbeing during the outbreak of the coronavirus such as implementing effective health measures, which, in turn, can protect the occupational health and safety aspects of the healthcare organizations. Their significant roles, as well as responsibilities in all the Covid-19 pandemic stages, are found to expose them to risks. The hazards that these healthcare workers have been immensely exposed to during this pandemic include psychological distress, pathogen exposure, fatigue, psychological violence, physical impacts, occupational burnout, extensive working hours, and stigma, among others (World Health Organization (WHO) 2021: 1). ${ }^{4}$ Even community health workers are found to be playing a vital role in facilitating successful COVID-19 vaccination programs. Health workers are found to plan, as well as coordinate the vaccine rollouts. They are also responsible for identifying the target groups for vaccination along with engaging communities, service delivery, facilitating mobilization, tracking progress, and conduct follow-ups (World Health Organization and the United Nations Children's Fund (UNICEF) 2021: 8). ${ }^{5}$

Additionally, Al Thobaitya and Alshammari ${ }^{6}$ asserted that healthcare workers and nurses have played a significant role in disasters and daily routine, especially during the COVID-19 pandemic. They are engaged in providing holistic care to all patients. Since nurses constitute many of the healthcare professionals, they have an important role within healthcare systems. Specifically,

Their roles in treating patients with COVID-19 involve triaging patients and detecting suspected cases with infections; providing essential treatment in an emergency and dealing with suspected patients with precautions; helping in decontamination and coordination with other healthcare providers; supplying holistic nursing practices in managing multiple infections simultaneously; playing critical roles in expanding care services; and dealing with relatives. ${ }^{6}$

However, Lahner et $\mathrm{al}^{7}$ stated that due to their pivotal role in maintaining the health and wellbeing of the patients even during Covid-19, health workers are found to be at a high risk of getting infected. In the context of Covid-19, it has highly influenced the dynamics of quality of life along with incorporating AI. This has been particularly highlighted in the scientific research conducted by Laudanski et al. ${ }^{8}$ In this study, it has been understood that technological advancements of AI have significant scope to improve the pandemic response at every stage. Appendix 1 illustrates the pandemic phases propounded by the WHO, wherein distinctive AI applications have been visible considering hypothetical cases. It shows that in the majority of all the stages, AI can be applied in one way or the other. It is during this pandemic that AI engines have been prominently performing with a higher level of sensitivity. This has helped to track cases along with the performance of response programs. Even in cases, wherei limited data are available, AI can be developed and deployed. However, pre-training of $\mathrm{AI}$ is found to be highly necessary so that appropriate outcomes can be attained. $^{9}$

Hence, with the consideration of the COVID-19 Pandemic, the transformation, which has been evident across the world concerning the quality of life as well as AI technological advancements, will be explored in this research paper. The key objective of this research paper is to perform an exploratory review of the varied dynamics of the COVID-19 pandemic, in addition to emphasizing the theme of pandemic morbidity and mortality. AI and its contributing role will also be reviewed. The reason for conducting this exploratory review on the concerned topic is to explore the pandemic dynamics, and its 
contribution in addressing such issues in the future. The present study indicates that it has a high contribution to the existing literature. This is because this topic can be relevant to other health and social issues. For understanding the literature gap, a literature review has been conducted. Thus, it must be noted that limited literature is present, which examines the dynamics of $\mathrm{AI}$ and QOL concerning the recent outbreak of the COVID-19 pandemic. Therefore, it can be evident that this study can provide important information concerning the QOL and AI dynamics during the pandemic.

\section{Method}

The method, which has been incorporated in this research study, is a review of the literature. Besides, anecdotal evidence along with exploratory reviews and reports on the morbidity of COVID-19 have also been taken into due consideration for understanding the dynamics of QOL and AI. This research paper also provides the scope of the devastating effects of the pandemic in select countries: a challenge that should awake all policymakers and create scope for more innovative, cost-effective, and pragmatic interventions. In that regard, the importance of supply chain management systems cannot be adequately emphasized. For the study, a literature review has been conducted by collecting reports and anecdotal evidence. Only recent sources have been selected or included for exploring the review. This is because the issue of the pandemic is recent. Hence, only recent sources are valid for the study. The sources before 2019 have been excluded from the study.

\section{Literature Review}

\section{Inequalities in the Age of COVID-19}

A troublesome pre-occupation in many affected regions is vulnerability. The notion that we are all equal in the fight against this virus has been quickly dispelled with early findings, revealing health inequalities amongst populations ranging from front-line service providers to marginalized communities to racial minority groups (Centers for Disease Control and Prevention (CDC) 2020). ${ }^{10}$

Specifically, in the United States (US), preliminary nationwide data released by the Centers for Disease Control and Prevention (CDC) ${ }^{11}$ revealed that although African Americans represent approximately 13\% of the US population, they accounted for $30 \%$ of all COVID-19 patients. Although far from complete, these data are consistent with the findings from other data collected on race and COVID-19 so far. A disproportionate toll is also being seen in the UK after the Guardian did an analysis of 12, 593 patients who died of COVID-19 as of April 19, 2020. It showed that $19 \%$ were Black, Asian, and minority ethnic (BAME) even though they make up $15 \%$ of the population. $^{12}$

\section{Economic Issues}

In many cases, keeping food on the table means foregoing safe working conditions and a greater risk of exposure to COVID-19. Hence, it can be stated that this issue closely aligns with pandemic morbidity: the focus of the present paper. Besides, a lack of economic resources often translates to food insecurity, amongst other things, which in turn often leads to poorer health outcomes that include a higher risk of underlying health conditions. In India, millions of people, including migrant laborers and daily wage earners, are facing hunger since the country's shut down in late March 2020 left them with no means to earn a living. A similar dire outlook is also threatening First Nations communities in Canada and black communities in the US. Canada does not report Coronavirus morbidity by race or ethnicity; making it difficult to address disparities. The study conducted by Nguyen further suggested that to eliminate such economic issues, AI technology can be implemented. In this context, it has been recommended that economic recovery can be predicted, as well as tracked with the help of AI applications by detecting cars and solar panel installations in parking lots. ${ }^{13}$

Many front-line workers like transport employees, sanitary workers, delivery personnel, etc., are often made up of BAME groups. ${ }^{14}$ In New York City, for example, Blacks and Latinos make up more than $60 \%$ of the hard-hit Metropolitan Transportation Authority (MTA). As of April 22, 2020, eighty-three MTA workers have died. ${ }^{15}$ Apart from them, healthcare workers are also found to be adversely affected due to COVID-19 economically. According to Shukla, Pradhan, and Malik, ${ }^{16}$ the outbreak of COVID-19 has posed an economic impact on the healthcare sector of India. As a result of which

A stimulus package at $0.8 \%$ of GDP was announced on 26 March 2020 and included in-kind and cash transfer to lower income households, insurance coverage of healthcare workers and financial support to low wage workers and others seeking jobs. ${ }^{16}$ 


\section{Basic Safeguards: Privilege for Some}

Even the most basic health recommendations to avoid contracting or spreading infection like hand washing and social distancing are major challenges in marginalized communities without sufficient access to water or housing. The number of people who do not have regular access to water is mind-boggling: 36 million people in Mexico, over 2 million in the US, more than 100 in First Nations communities in Canada, 63.4 million in India, etc. In all, 40\% of the world's population lack access to basic handwashing facilities in their homes. ${ }^{17-20}$

The inability to self-isolate, when faced with a virulent virus, places additional stress on people within communities, who are affected by overcrowding and housing shortages. In many Indigenous communities in Canada often living in remote areas with limited medical services there are sometimes two or three families living in the same house. ${ }^{21}$ Indigenous Australians face the same troubling dilemma, compounded by a higher prevalence of underlying health conditions in Indigenous communities compared to general populations. ${ }^{21}$ There is compelling evidence that unprecedented measures such as national lockdowns were incorporated in Italy due to the pandemic. The main reason for undertaking such measures was that Italian people were facing several health issues, including psychological issues. Even post-traumatic symptoms were evident and hence, psychological interventions were suggested in the study present by Roma et al. ${ }^{22}$

For Brazil's Indigenous groups, where some have little or no contact with non-Indigenous society leaves them particularly vulnerable to disease. Fears grow that the entire community could be wiped out amidst a rising number of illegal land invasions from loggers, miners, etc. As of April 17, 2020, Brazil's Socio-Environmental Institute (ISA) has recorded at least 27 confirmed COVID19 cases and 3 deaths, including a 15-year-old from a village on the Uraricoera River - an access route for gold rush miners. ${ }^{23}$ Besides, in South-East Asia, it has been reported that Covid-19 was evident earlier than in other parts of the world. The concerned states took 17 days to declare an emergency ie, after 50 positive cases of the contamination of the virus. ${ }^{24}$ Similarly, several African nations have recorded lesser than 1000 cases. Specifically,

WHO has warned that the pandemic could kill between 83,000 and 190,000 people in 47 African countries in the first year, mostly depending on governments' responses; and the virus could 'smolder' for several years. ${ }^{25}$

\section{Impact of Covid-19 on Health Workers}

Based on the understanding derived from the preliminary research, it has been found that due to the significant roles and responsibilities undertaken by the healthcare workers, they become prone to being infected by the virus. This is the reason why Lahner et al. affirmed that there is a high prevalence of COVID-19 infection among healthcare workers. This was prominently evident from the cross-sectional study, which was done considering the retrospective data of healthcare workers. The results of this study showed that

A total of 2057 HWs (median age 46, 19-69 years, females $60.2 \%$ ) were assessed by the RNA RT-PCR assay and $58(2.7 \%)$ tested positive for SARS-CoV-2 infection. Compared with negative HWs, SARS-CoV -2-positives were younger (mean age 41.7 versus 45.2, $\mathrm{p}<0.01 ; 50 \%$ versus $31 \%$ under or equal to 40 years old, $\mathrm{p}<0.002)$ and had a shorter duration of employment (64 versus 125 months, $p=0.02$ ). Exposure to SARS-CoV -2 was more frequent in positive HWs than in negatives $(55.2 \% \text { versus } 27.5 \%, \mathrm{p}<0.0001)^{7}$

It was further observed that nearly half of the healthcare workers considered for this study were not exposed to any COVID-19 infected subjects. This helps in assesing the vulnerability of the healthcare workers while dealing and responding to the pandemic because they are playing the essential role of the frontline workers. ${ }^{7}$ This study is found to significantly contribute to the literature review. The main reason being that in conducting vaccination drives, the healthcare professionals have important roles. However, if they are affected, the healthcare programs may not lead to positive outcomes. This study can be used in the future for exploring the situations and understanding the risks that are associated with frontline workers so that the third wave of COVID-19 can be managed appropriately along with responding to future healthcare issues.

\section{Discussion}

\section{Impact of Covid-19 on the Way and Quality of Life}

While lockdowns continue to serve as a geopolitical prevention strategy against COVID-19, the financial and economic outcomes on the poor populations undoubtedly are remarkably onerous. In Asia, for example, and according to the Economic and Social Commission for Asia and the Pacific (ESCAP), 70\% of workers belong to the informal economy (no benefits or safety net). ${ }^{26}$ Many countries in this region have introduced support mechanisms - 
financial and economic (rice, sugar, etc.). These strategies are necessary but not sufficient! As demonstrated by the lockdown insubordination in countries like Bangladesh, the poor in these economies remain vulnerable with limited options and an extremely unenviable way of life: contract the virus by risking going out or follow the lockdown and starve.

The biggest concern for the World Health Organization (WHO) is COVID-19's potential to spread in countries with weak health systems. While the 2019 Global Health Security Index, a health security assessment listing of 195 countries, highlighted fundamental weaknesses of healthcare systems around the world, it's not surprising that many countries found to be the least prepared were in Africa. ${ }^{27}$ Less than $50 \%$ of the continent's population has access to modern health facilities and countries are plagued with shortages ranging from low numbers of healthcare workers in ratio to the population to medical equipment, medications, and capacity (AFRIC 2019). ${ }^{28}$

Densely populated cities, slums, and displacement camps; struggles with other simultaneous communicable diseases, ongoing conflicts in some regions, and myriads of other dangerous conditions, make it inevitable that the continent will experience a substantial epidemic.

The one silver lining in terms of mortality rates is that Africa has the youngest population in the world $-60 \%$ of its 1.25 billion population is under the age of twenty-five, an age group likely to recover from COVID-19 infection.

Besides, data collected from the Chinese Center for Disease Control and Prevention (China CDC) in January and February 2020, identified people aged 60 and over as the most vulnerable to COVID-19. Mortality rates based on these findings were determined by University of Bern researchers as $4.6 \%$ for ages $60-69,9.8 \%$ for ages $70-79$, and $18 \%$ for ages 80 and over.

Unsurprisingly, with $23.1 \%$ of Italy's population being 65 and over, it has one of the highest mortality rates in the world (28,236 as of May 1, 2020). In Canada, 79\% of all deaths in the country have been linked to seniors' homes and long-term care facilities as of April 13, 2020, according to chief public health officer Theresa Tam. Similarly, as per the study conducted by Bhapkar et al, the mortality rate during the pandemic is constantly altering with time and hence, it has been termed „Progressive Mortality Rate $(\mathrm{PMR})$, . In this study, it was observed that the PMR rates of Russia, India, Japan, the US, Brazil, Germany, China, Mexico, Singapore, New Zealand, and Canada were 1.83, $2.82,2.75,3.61,3.92,4.35,5.34,12.79,0.05,1.4$, and
7.63 respectively. On the other hand, Progressive Recovery Rates (PRR) of the same countries were recorded to be $85.58,106.44,101.15,38.89,96.53$, $94.85,94.44,95.6,97.93,97.7$, and 92.63 accordingly. $^{29}$

Furthermore, the study of Samlani et al, suggested that in Morocco, the 'quality of life of the people was moderately affected by the pandemic. This was because the Mental Health Score (MCS) of all the participants was 34.49. On the other hand, their Physical Health Score (PCS) accounted for 36.10. It was also found that the impact of the concerned pandemic was evident in those people with chronic illnesses, which significantly deteriorated their wellbeing and quality of life. The main reason for such results is that people with or without chronic illness were found to suffer from mental health and panic issues. Besides, the isolation and quarantine made people face psychological health problems. ${ }^{30}$ It has also been observed that Covid-19 has led to the death of several people, which has further affected the food systems and presented unprecedented challenges to work-life and public health. ${ }^{31}$

On the other hand, as of March 2021, a total of $1,521,068$ people have been infected by the pandemic in South Africa and the most affected region was Gauteng (Johannesburg), which reported about 406,729 Covid-19 cases. It was also found that the highest increase in the daily cases of Coronavirus was evident on 8th January 2021 with 21, 980 new cases. Besides, viewing from a different perspective, it has been found that the pandemic significantly hampered the businesses across the nation, thereby adversely affecting their survivability at large. $^{32,33}$ This indicates that South Africa has been largely affected by the pandemic, which is bound to change the quality of life of people living and working therein. Concerning South Africa, Covid-19 largely influenced the deaths and mortality rates of the nation due to the presence of underlying causes. It has made a significant impact on the quality of life. Contextually, the mental health of people was negatively affected by the pandemic due to the uncertainty that it created. Besides, restrictions, quarantine, financial losses, high infectivity, continuous lockdowns, fatality, and unemployment rates have altered the daily lives, as well as activities of people. This has led problems associated with mental health along with substance abuse. Even educational institutions have remained closed, which negatively affected the learning and teaching activities of people. Even teenage marriages were observed to increase along with gender-based violence, 
demonstrations, and social unrest. This implies that there are less human capital and economic opportunities in the future of the nation. ${ }^{34}$

Another study conducted by Guo et al portrayed those lockdowns, which have been implemented as a precautionary measure during the Covid-19 pandemic have significantly influenced the "quality of life of people with Parkinson's disease (PD). In this regard, it was found that the concerned patients were unable to seek medical advice or guidance from their respective doctors. As a result, most of the patients had to alter their routine medicines, which made their quality of life or health conditions even worse. In such situations, telemedicine is found to be significantly effective and efficient for the patients during the lockdown. The challenges concerning adequate treatment caused the symptoms of patients to get aggravated, which further exacerbated their 'quality of life. On the other hand, healthcare professionals are also finding it difficult to maintain healthcare quality. ${ }^{35,36}$ Zhang and Ma further affirmed from their study that the 'quality of life, as well as mental health of local people, especially that of China has deteriorated significantly. Specifically, a mild level of stress was evident among most of the survey participants irrespective of the devastating pandemic outbreak. The mean Impact of Event Scale (IES) score was found to be $13.6 \pm 7.7 .{ }^{37}$ Even social and economic developments have been adversely affected, thereby increasing poverty along with inequality. ${ }^{38}$ All these aspects indicate that Covid-19 has largely affected people throughout the world, thereby transforming the way they live or their quality of life.

On a similar note, Dey et al highlighted that because of COVID-19, there are several psychosocial and psychological impacts: especially fear among the public. In this review, it was particularly found that the psychological effect was more taxing. Hence, long-term quarantine was implemented by the governmental bodies of various countries. This is the reason why boredom, fear, and frustration have been observed to be highly evident among the citizens. This has increased the difficulties in the trying times of the Covid-19 outbreak. The latter stages of the pandemic were observed to pose more significant impacts such as psychological disorder and stress along with mental stigma and financial losses. This study found that $22 \%$ of adults (a survey among 1000 people) have been experiencing worse sleep patterns during this pandemic, which may increase the risk of cardiovascular events [9]. In this situation of adversity, yoga, meditation, and video chat with relatives and friends induce mental relaxation, to some extent. In contrast, self-isolation gives us opportunities to connect with our passions and inner identity. ${ }^{39}$

Additionally, AI along with augmented intelligence plays a significant role in understanding the collected data through data analytics, pattern recognition, anomaly detection, and machine learning. ${ }^{40}$ Similarly, Mukherjee et al stated that AI-driven tools have been used to track as well as observe the developments of positive cases during the outbreak of the pandemic. However, it was argued that differences in data can influence the critical decision-making concerning the preparedness and responses of the pandemic. With the advancement in the pandemic stages, technical innovations concerning AI have also been evident, especially for detecting and predicting purposes. ${ }^{41}$

\section{Current Achievements During Covid-19}

Currently, there are several achievements, which have been evident during the outbreak of a pandemic. According to report findings of United Nations, telephoneenabled services such as teleconferencing along with social media and other smartphone applications as well as online shopping have been increasing. These services are used to resolve the problems due to Covid-19 in most of the nations, including the US and China. These improvements have increased e-commerce business activities and forced traditional businesses to undergo digitalization. ${ }^{42}$ In the social context, one of the positive aspects, which have been highlighted by the pandemic, is the role and contribution of women in society. Cities and communities have facilitated innovation for achieving sustainable developments even in this crisis. Besides, marine, as well as land ecosystems are also improving during this pandemic due to reduced exploitation of resources. Also, due to lockdowns and isolations, the flora and fauna are being restored in their natural habitat, as they are not disturbed by humans. Another positive aspect of this pandemic is the unity with which people have been fighting against Coronavirus. ${ }^{43,44}$ Furthermore, Covid-19 has facilitated the importance of distance learning. However, there are students, who are facing problems in switching to the online mode of learning due to the lack of adequate resources and support from their parents IESALC 2020: 45; UNESCO 2020). ${ }^{45-47}$ On the contrary, Gonzalez et al ${ }^{48}$ affirmed that the confinement evident due to Covid-19 had a positive impact on the performance of the students in Spain. Similarly, it was found in the study conducted by 
Chaudhary, Gupta, Jain, and Santosh that the air quality was considerably improved during the lockdown phase of the COVID-19 pandemic in most nations. Hence, it can be stated that due to COVID-19, isolation practices were implemented, which proved to be climate favorable. In many regions of the US, Brazil, China, and India, air quality indices improved due to restrictions in air pollution activities. ${ }^{49}$ Besides, currently, big data and AI incorporation have been evidenced to enhance the pandemic situation and reduce the adverse impacts of COVID-19. In this context, it was found that "By training on an open-source dataset with 13, 975 images of 13, 870 patients, the proposed CNN model can achieve an accuracy of 93.3\%." (p. 5) ${ }^{50}$ Herein, CNN model refers to the convolution neural network (CNN), which incorporates AI techniques. ${ }^{50}$

\section{Post-Pandemic Ethical Issues}

Ethical issues are being faced in several areas during the pandemic, especially in terms of physical distancing, conducting clinical trials, rights of healthcare workers, priority-setting, public health surveillance, and resource allocation. The ethical issues are mainly at the time of conducting healthcare research, policy-making, and decision-making process. ${ }^{51}$ Hence, ethical aspects must be closely considered while responding to the issue at the post-pandemic stage. Specifically, ethical concerns have emerged with the increase in the influx of patients requiring ICUs. Healthcare professionals have been facing ethical dilemmas along with life-support withdrawal decisions. Similar issues have also been faced concerning the "quality of end-of-life support" and family visits. Hence, effective triage policies are to be formulated so that these issues may not be faced in the post-pandemic phase. ${ }^{52}$ Similar aspects have been highlighted by McGuire et al wherein it has been affirmed that ethical issues emerged not only within the healthcare system but also in society. Particularly, ethical issues can be evident while defining the benefits, handling informed consent, understanding the special needs of other patients, mitigating discrimination, identifying structural inequalities, and engaging communities. ${ }^{53}$ Ethical issues have also been found to emerge at the time of resetting healthcare services after the outbreak ie, post-pandemic. ${ }^{8}$ Contextually, it has been affirmed in the study of Laudanski et al that

Numerous predictive models of COVID-19 prognosis in various individuals based on AI-driven algorithms have been designed and published [75-80]. Their ability to distinguish between favorable outcomes and demise is significantly accurate. A few of them were implemented to test their suggestions in real life, a fact that leaves unaddressed concerns about dataset impartiality and concomitant ethical concerns about the implication of AIdriven decisions.

This indicates that in the post-pandemic era, ethical concerns have been prominent, especially at the time of implementing AI-driven decisions. ${ }^{54}$

\section{Contribution of $\mathrm{Al}$ in Accelerating Covid-1 9 Vaccine Discovery}

The latest technology has been of utmost importance during the pandemic. This is because AI is found to be effective not only in detecting pathogens but also in responding and recovering from Covid-19. According to a report presented by OECD, AI systems had predicted an outbreak of pneumonia in China before coronavirus became the worldwide threat. Hence, understanding the effectiveness of this technology, it is clear that AI technologies and tools can be incorporated for supporting the efforts of medical communities, policymakers, and societies. This can enable the concerned authorities to manage activities at all stages of the pandemic, including the acceleration of research, detection, response, prevention, and recovery. AI can be effective in enhancing research for the discovery of proper solutions such as vaccines and drugs through distributed computing and open data projects. ${ }^{55}$ Similar opinions have been provided by Arora, Banerjee, and Narasu, wherein AI largely contributed to developing several types of vaccines to date. It seemed that there is a race between the virus and vaccine developers. Hence, for the betterment of mankind and to improve the situation created by the pandemic, AI's ability continues to be vital. This was because "The pace of the discovery can be accelerated manifold by harnessing the power of $\mathrm{AI}$ ". ${ }^{56}$

To win in the race, several biotechnology companies are depending on AI such as Blue Dot for pacing up the ways to find a cure for the virus. This technology has the potential to identify changes and spot patterns so that the process of vaccine development does not get hampered. In this context, several successful trials have been made. For instance, the "Deep Learning-Based Drug Screening" method was created using DenseNet for predicting the interactions between ligands and proteins, which further helped in determining 
the drug combination that worked well while responding to Covid-19. Besides, DeepMind has used the AlphaFold library for understanding the protein structure of the virus. Furthermore, Machine learning (ML) models were developed by the AI scientists of Wuhan for identifying the infection intensity with the help of factors such as gender and age. ${ }^{57}$ As a result of such initiatives, an "AI-based flu vaccine" has been developed in the US for which the clinical trials are being sponsored by the National Institute of Allergy and Infectious Diseases. The scientists of Flinders University used "synthetic chemist", which is an AI program that generated numerous synthetic compounds. They also used the Search Algorithm for Ligands (SAM), which is an AI program that assisted the scientists to determine good candidates for vaccine trials. This program has shortened the development process of vaccines. This indicates that AI can contribute not only to examine the drugs that are currently available but also helps in accelerating the antivirus development procedure. ${ }^{58}$ Additionally, the Human Vaccines Project, as well as the Harvard T.H. Chan School of Public Health, has started the "Human Immunomics Initiative".This initiative made use of AI models to speed up the process of vaccine and therapeutic development, thereby understanding effective immunity concerning old-aged populations. ${ }^{59}$

\section{Implications and Lessons Learned from the Pandemic}

The pandemic has also illustrated that with cooperation at the local, national, and global levels communities can thrive in the wake of the crisis. ${ }^{60}$ It has also been understood that at the time of pandemic without effective control and prevention measures, the healthcare systems become restricted when considering general measures such as limited travel, social contact, hygiene and sanitary measures, usage of PPE, isolation, and quarantine. ${ }^{61,62}$ The ongoing carnage experienced by this population is not only despicable but also confirms the degree of incompetence and lackadaisical efforts of some institutions - both government and private.

As counterfactuals, there are compelling needs to know if these gruesome and unacceptable mortality rates could have been avoided if:

- effective oversights were in place;

- periodic reports were produced and submitted to the relevant parties and at different levels of the institutions;
- relevant and appropriate feedback was part of the process;

- monitoring, evaluation, and learning were in place;

- role of AI and related technology in developing vaccines and drugs;

- effective operating strategies were in place and more.

The memories of this pandemic in these vulnerable communities will be long-lasting and tenuous, especially between the affected families and these institutions.

Additionally, it must also be noted that communities need to prioritize and appreciate essential values along with their needs so that the true importance of healthcare professionals and frontline workers in maintaining the wellbeing of people can be understood. Even the businesses require focusing on values and fulfill the needs of the people. Piccialli et al affirmed that AI technologies have the potential to be successfully used in healthcare systems so that society can be benefitted in future pandemic situations. ${ }^{63}$

\section{Strategic Post-Pandemic Requirements}

Irrespective of several positive achievements evident during the pandemic due to lockdowns and less human intentions on social, business, and environmental aspects, it has posed significant adverse impacts. To minimize or mitigate the negative consequences of the Covid-19 pandemic, certain strategic decisions need to be undertaken by the nations at the post-pandemic stage. Innovation has been one of the widely used strategic initiatives to be undertaken by several countries, especially to revive the healthcare systems along with gain economic stability. ${ }^{64}$ On the other hand, a recent Organisation for Economic Co-operation and Development (OECD) report highlighted that the social economy has been playing an essential role in addressing or minimizing the impacts of the pandemic. This indicates that nations must focus on strengthening their social economies so that both long-term and short-term impacts can be eliminated during the post-pandemic phase. This is because social economy firms have the potential to reshape the national economy, thereby encouraging sustainable economic along with inclusive models. This, in turn, can facilitate social innovation, which will help the economy to improve in the future. ${ }^{65}$ It has also been suggested by Piccialli et al that in the post-pandemic era, careful application of AI technologies must be enabled for managing complex situations similar to COVID-19 in the future, thereby involving research, healthcare, and society. ${ }^{63}$ 


\section{Future Implications}

As we go through these trying times, there is a need to regularly remind ourselves that while the vulnerable groups on the front lines specifically continue to subject themselves to this devastating virus, their motivation and dedication to respond to this professional call of duty requires special recognition, empathy, and compassion at all levels. This applies specifically to health professionals who continue to expose themselves daily to alleviate the suffering of victims of the pandemic. Institutional support remains relatively inadequate and yet its involvement is a sine qua non that cannot be adequately emphasized. Institutional support needs to be strengthened, especially concerning individual risks and supply chain coordination.

In the future, it will be important to take effective public interventions so that new cases of Covid-19 can be prevented along with mitigating community transmission. Besides, innovation must be taken into consideration for tracing cases along with online learning and telemedicine for managing the second wave of the Covid-19 outbreak more effectively than the earlier one. ${ }^{66}$ Since the second wave has been phased out; recommendations for the third wave must be taken into consideration. Vigilant monitoring of the cases must be maintained for tracking the new variants to control the cases at the earliest. ${ }^{67}$ Disparities evident during the pandemic must also be eliminated cooperatively in order to ensure that future pandemics and similar issues can be averted effectively. Additionally, the health issues such as anxiety and stress must be evaluated, as well as addressed immediately among the healthcare staff. ${ }^{68}$ It has also been understood that elderly people have higher risks of transmission, which suggests that in the future, the healthcare requirements of the older citizens must be taken into high consideration so that their safety and wellbeing can be ensured. ${ }^{62}$ Besides, the importance of AI technology has also been found to be immensely imperative, as it has been estimated to play a vital role in tackling COVID-19. AI can contribute not only to pacing up the vaccine development procedure but also in identifying future threats posed by viruses beforehand. It also helps in diagnosing, predicting infections, surveillance, gathering information, delivering materials, deploying services, and tracking the recovery process, thereby expanding strategies. Evidence of these implications has not been evident to date. This can be highly effective in tackling Covid-19 in the future. ${ }^{65}$ Additionally, AL-Hashimi and Hamdan asserted that AI has been showing positive results in detecting conditions such as diseases. It must also be effectively used in the healthcare sector. With its implentation, healthcare organizations can track the progress of any situation at a quick pace. With more advancement in AI-driven technologies, higher-quality healthcare services can be delivered for the betterment of society. ${ }^{69}$

\section{Conclusions}

Based on the findings gathered in the above sections, it has been understood that Covid-19 has significantly affected the world both positively and negatively. It can be concluded that the pandemic has facilitated global transformations, especially by deteriorating the quality of life of millions of people. Additionally, the public along with healthcare workers was also found to be adversely affected due to COVID-19. It became highly important on the part of the healthcare workers that their health and safety were maintained in order to perform their duties effectively. On a positive note, COVID-19 has made the best use of AIdriven technologies for aiding or responding to the pandemic. Hence, it has been suggested that its full potential needs to be explored in the future. This can help in providing better quality healthcare services in pandemic situations in the future both efficiently and effectively. This will confirm that the objective of the research study has been met effectively. Finally, an exploratory review of COVID-19 has been conducted by emphasizing the theme of pandemic morbidity and considering the dynamics of AI and Quality of Life (QOL).

The pandemic also made us realize the importance of cooperation among people along with values. It is also understood that healthcare workers and other frontline workers are vital in responding to the pandemic. Additionally, innovative approaches and effective health interventions are found to be essential in addressing the adverse consequences of the crisis. This further indicates the lessons that must be learned from the pandemic so that new waves and future epidemics can be handled as effectively as possible. One of such future implications is to ensure the health and wellbeing of elderly people. Another important future implication is to optimally utilize AI capabilities to tackle the pandemic throughout its different stages.

\section{Funding}

Personal Funds.

\section{Disclosure}

The author reports no conflicts of interest for this work. 


\section{References}

1. Chatterjee P, Nagi N, Agarwal A, et al. The 2019 novel coronavirus disease (COVID-19) pandemic: a review of the current evidence. Indian J Med Res. 2020;151(2-3):147-159.

2. Salyer SJ, Maeda J, Sembuche S, et al. The first and second waves of the COVID-19 pandemic in Africa: a cross-sectional study. The Lancet. 2021;397(10281):1265-1275.

3. Martini M, Gazzaniga V, Bragazzi NL, Barberis I. The Spanish Influenza Pandemic: a lesson from history 100 years after 1918. J Prev Med Hyg. 2019;60(1):E64-E67.

4. World Health Organization (WHO). Coronavirus Disease (Covid-19) Outbreak: Rights, Roles and Responsibilities of Health Workers, Including Key Considerations for Occupational Safety and Health. World Health Organization. 1-3. 2021.

5. World Health Organization and the United Nations Children's Fund (UNICEF). The Role of Community Health Workers in COVID-19 Vaccination: Implement Support Guide. 2021;1-15.

6. Al Thobaitya A, Alshammari F. Nurses on the Frontline against the COVID-19 pandemic: an integrative review. Dubai Med J. 2020;3:87-92.

7. Lahner E, Dilaghi E, Prestigiacomo C, et al. Prevalence of Sars-Cov2 Infection in Health Workers (HWs) and diagnostic test performance: the experience of a teaching hospital in central Italy. Int J Environ Res Public Health. 2020;17(12):1-12.

8. Laudanski K, Shea G, DiMeglio M, Rastrepo M, Solomon C. What can covid-19 teach us about using AI in pandemics? Healthcare. 2020;8:1-14.

9. Laudanski K, Shea G, DiMeglio M, Rastrepo M, Solomon C. What can covid-19 teach us about using AI in pandemics? Healthcare. 2020;8:1-14.

10. Centers for Disease Control and Prevention (CDC). Cases in US; 2020. Available from: https://www.cdc.gov/coronavirus/2019-ncov /cases-updates/cases-in-us.html.Accessed April 30, 2020.

11. Centers for Disease Control and Prevention (CDC). Cases in US; 2020. Available from: https://www.cdc.gov/coronavirus/2019-ncov /cases-updates/cases-in-us.html. Accessed April 30, 2020.

12. The Guardian. Ethnic minorities dying of Covid-19 at higher rate, analysis shows; 2020. Available from: https://www.theguardian.com/ world/2020/apr/22/racial-inequality-in-britain-found-a-risk-factor-for -covid-19. Accessed April 30, 2020.

13. Nguyen TT. Artificial Intelligence in the Battle Against Coronavirus (COVID-19): A Survey and Future Research Directions. Deakin University; 2020: 1-13.

14. The Metropolitan Transportation Authority. Diversity committee meeting. Available from: http://web.mta.info/mta/news/books/ archive/170221_1415_Diversity.pdf. Accessed April 3, 2020.

15. Politico. With death toll hitting 83, the MTA contemplates a memorial for its Covid fallen. Available from: https://www.poli tico.com/states/new-york/albany/story/2020/04/22/with-death-tollhitting-83-the-mta-contemplates-a-memorial-for-its-covid-fallen -1279032. Accessed April 30, 2020.

16. Shukla D, Pradhan A, Malik P. Economic impact of COVID-19 on the Indian healthcare sector: an overview. Int J Comm Med Public Health. 2021;8(1):489-494.

17. The Council of Canadians. Fighting covid-19 starts with universal access to water and sanitation; 2020. Available from: https://cana dians.org/analysis/fighting-covid-19-starts-universal-access-waterand-sanitation. Accessed April 30, 2020.

18. United Nations. UN Water; n.d.. Available from: https://www. unwater.org/water-facts/handhygiene/. Accessed April 30, 2020.

19. US Water Alliance. Closing the water access gap in the United States; 2020. Available from: http://uswateralliance.org/sites/uswateralli ance.org/files/Closing $\% 20$ the $\% 20$ Water $\% 20$ Access $\% 20$ Gap $\% 20 \mathrm{in} \%$ 20the\%20United\%20States_DIGITAL.pdf. Accessed April 30, 2020.
20. WaterAid. India ranked first in the world for most rural people without access to clean water; 2020. Available from: https://www.water aidindia.in/media/india-ranked-first-in-the-world-for-most-ruralpeople-without-access-to-clean-water. Accessed April 30, 2020.

21. Statistics Canada. List of health indicators by aboriginal and non-aboriginal populations; 2020. Available from: https://www150. statcan.gc.ca/n1/pub/82-624-x/2013001/article/app/11763-01-app1eng.htm. Accessed April 30, 2020.

22. Roma P, Monaro M, Colasanti M, et al. A 2-month follow-up study of psychological distress among Italian people during the COVID-19 lockdown. Int J Environ Res Public Health. 2020;17(21):8180. doi:10.3390/ijerph17218180

23. Cowie S. Brazil indigenous fear coronavirus decimate communities. Aljazeera; 2020. Available from: https:// www.aljazeera.com/indepth/features/brazil-indigenous-fear-corona virus-decimate-com munities-200421130720967. html. Accessed May 1, 2020.https://www.aljazeera.com/indepth/fea tures/brazil-indigenous-fear-coronavirus-decimate-communities200421130720967.html

24. United Nations. Policy Brief: The Impact of Covid-19 on South-East Asia. UNESCAP; 2020a: 2-29.

25. United Nations. Policy Brief: Impact of Covid-19 in Africa. UN; 2020b: 2-28.

26. UNESCAP. The impact and policy responses for covid-19 in Asia and the Pacific. Available from: https://www.unescap.org/sites/default/ files/COVID\%20_Report_ESCAP.pdf. Accessed May 1, 2020.

27. Global Health Security Index. Welcome to the 2019 Global Health Security Index; 2020. Available from: https://www.ghsindex.org/. Accessed April 30, 2020.

28. AFRIC. Africa's health care system in need of more financing. Available from: https://afric.online/10961-africas-health-care-systemin-need-of-more-financing/. Accessed April 30, 2020.

29. Bhapkar HR, Mahalle PN, Dey N, Santosh KC. Revisited COVID-19 mortality and recovery rates: are we missing recovery time period? J Med Syst. 2020;44(12):1-5. doi:10.1007/s10916-020-01668-6

30. Samlani Z, Lemfadli Y, Errami AA, Oubaha S, Krati K. The impact of the COVID-19 pandemic on quality of life and well-being in Morocco. Arch Commun Med Public Health. 2020;6(2):130-134. doi:10.17352/2455-5479.000091

31. Chriscaden K Impact of COVID-19 on people's livelihoods, their health and our food systems; 2020. Available from: https://www.who.int/news/ item/13-10-2020-impact-of-covid-19-on-people's-livelihoods-theirhealth-and-our-food-systems. Accessed March 11, 2021.

32. Galal S. Coronavirus (COVID-19) cases in South Africa as of March 7, 2021, by region; 2021. Available from: https://www.sta tista.com/statistics/1108127/coronavirus-cases-in-south-africa-byregion/\#: :text=Regionally\%2C\%20Gauteng\%20(Johannesburg) $\%$ 20 was, and $\% 20278 \% 2 \mathrm{C} 883 \% 20$ coronavirus $\% 20$ cases $\% 2 \mathrm{C} \% 20$ respec tively. Accessed March 112021.

33. Galal S Number of new daily coronavirus (COVID-19) cases in South Africa as of March 7, 2021; 2021a. Available from: https:// www.statista.com/statistics/1107993/coronavirus-cases-in-southafrica/. Accessed March 11, 2021.

34. Mbunge E. Effects of COVID-19 in South African health system and society: an explanatory study. Diabetes Metabol Syndr. 2020;14 (6):1809-1814. doi:10.1016/j.dsx.2020.09.016

35. Guo D, Han B, Lu Y, et al. Influence of the COVID-19 pandemic on quality of life of patients with Parkinson's disease. Parkinson's Dis. 2020;1-6.

36. Haleem A, Javaid M, Vaishya R. Effects of COVID 19 pandemic in daily life. Current Med Res Pract. 2020;10(2020):78-79. doi:10.1016/ j.cmrp.2020.03.011

37. Zhang Y, Ma ZF. Impact of the COVID-19 pandemic on mental health and quality of life among residents in Liaoning Province, China: a cross-sectional study. Int $J$ Environ Res Public Health. 2020;17(7):1-12. 
38. Millard J. Impacts of COVID-19 on Social Development and Implications for the Just Transition to Sustainable Development. United Nations; 2020: 1-10.

39. Dey N, Mishra R, Fong SJ, Santosh KC, Tan S, Crespo RG. COVID19: psychological and psychosocial impact, fear, and passion. Dig Govt. 2020;2(1):1-4.

40. Santosh KC. COVID-19 prediction models and unexploited data. J Med Syst. 2020;44(9):1-4. doi:10.1007/s10916-020-01645-z

41. Mukherjee H, Dhar A, Obaidullah SM, Santosh KC, Roy K. COVID19: a necessity for changes and innovations. In: COVID-19: Prediction, Decision-Making, and Its Impacts. Springer Nature Singapore Pte Ltd; 2021:99-105.

42. United Nations. Impact of the Covid-19 Pandemic on trade and development. United Nations Conference on Trade and Development, 2020 4-112. Available from: https:/unctad.org/system/ files/official-document/osg2020d1_en.pdf. Accessed August 24,2021.

43. Gulseven O, Al Harmoodi F, Al Falasi M, ALshomali I. How will the COVID-19 pandemic affect the UN sustainable development goals (SDGs)? SSRN Elec J. 2020;1-28. doi:10.2139/ssrn.3592933

44. Srivastava A, Sharma RK, Suresh A. Impact of Covid-19 on sustainable development goals. Int J Advan Sci Technol. 2020;29(9 Special Issue):4968-4972.

45. Di Pietro G, Biagi F, Costa P, Karpinski Z, Mazza J. The likely impact of COVID-19 on education: reflections based on the existing literature and recent international datasets. JT Rep. 2020;1-46. doi:10.2760/126686

46. IESALC. COVID-19 and Higher Education: Today and Tomorrow. The UNESCO International Institute for Higher Education in Latin America and the Caribbean 2020; 1-46.

47. UNESCO. UNESCO's key achievements in 2020 with the specific focus on COVID-19; 2020. Available from: https://en.unesco.org/ news/unescos-key-achievements-2020-specific-focus-covid-19. Accessed March 11, 2021.

48. Gonzalez T, De La Rubia MA, Hincz KP, et al. Influence of COVID19 confinement on students' performance in higher education. PLoS One. 2020;15(10):1-23. doi:10.1371/journal.pone.0239490

49. Chaudhary A, Gupta V, Jain N, Santosh KC. COVID-19 on air quality index (AQI): a necessary evil? COVID-19. In: Prediction, Decision-Making, and Its Impacts. 2021;127-137.

50. Pham QV, Nguyen DC, Hwang WJ, Pathirana PN. Artificial intelligence (AI) and big data for coronavirus (COVID-19) pandemic: a survey on the state-of-the-arts. IEEE Access. 2020;4:1-19.

51. WHO. Ethics and covid-19; 2021. Available from: https://www.who. int/teams/health-ethics-governance/diseases/covid-19. Accessed April 30, 2020.

52. Robert R, Kentish-Barnes N, Boyer A, Laurent A, Azoulay E, Reignier J. Ethical dilemmas due to the Covid-19 pandemic. Ann Intensive Care. 2020;10(1):1-9. doi:10.1186/s13613-020-00702-7

53. McGuire AL, Aulisio MP, Davis FD, Erwin C, Harter TD, Jagsi R. COVID-19 Task Force of the Association of Bioethics Program Directors (ABPD). Ethical challenges arising in the COVID-19 pandemic: an overview from the Association of Bioethics Program Directors (ABPD) task force. Am J Bioethics. 2020;20(7):15-27. doi:10.1080/15265161.2020.1764138
54. Baines P, Draper H, Chiumento A, Fovargue S, Frith L. COVID-19 and beyond: the ethical challenges of resetting health services during and after public health emergencies. $J$ Med Ethics. 2020;46 (11):715-716. doi:10.1136/medethics-2020-106965

55. OECD. Using artificial intelligence to help combat COVID-19. Tackling Coronavirus (Covid-19). Contribut Global Effort. 2020a;2-5.

56. Arora N, Banerjee AK, Narasu ML. The role of artificial intelligence in tackling COVID-19. Future Virol. 2020;1-8. doi:10.2217/fvl2020-0130

57. Kannan S, Subbaram K, Ali S, Kannan H. The role of artificial intelligence and machine learning techniques: race for covid-19 vaccine. Arch Clin Infect Dis. 2020;15(2):2-9. doi:10.5812/ archcid. 103232

58. Ahuja AS, Reddy VP, Marques O. Artificial Intelligence and COVID19: A Multidisciplinary Approach. Elsevier; 2020:1-8.

59. Kaushik AC, Raj U. AI-driven drug discovery: a boon against COVID-19? AI Open. 2020;1:1-4. doi:10.1016/j.aiopen.2020.07.001

60. Snower DJ Fundamental lessons from the COVID-19 pandemic; 2021. Available from: https://www.global-solutions-initiative.org/ press-news/fundamental-lessons-from-the-covid-19-pandemic-global -solutions-summit-2020-opening-address/?cn-reloaded=1. Accessed April 30, 2020.

61. Mijović B. COVID-19 - lessons learned. Scr Med. 2020;51(1):1-5.

62. Brannen S Covid-19 reshapes the future; 2020. Available from: https://www.csis.org/analysis/covid-19-reshapes-future. Accessed March 11, 2021.

63. Piccialli F, di Cola VS, Giampaolo F, Cuomo S. The role of artificial intelligence in fighting the covid-19 pandemic. Inf Syst Front. 2021;1-31. doi:10.1007/s10796-021-10131-x

64. Khetrapal S, Bhatia R. Impact of COVID-19 pandemic on health system \& Sustainable Development Goal 3. Ind J Med Res. 2020;151 (5):395-399. doi:10.4103/ijmr.IJMR_1920_20

65. Organisation for Economic Co-operation and Development (OECD). Social Economy and the COVID-19 Crisis: Current and Future Roles. Tackling Coronavirus (Covid-19): Contributing to a Global Effort. 2020:2-25

66. Salyer SJ, Maeda J, Sembuche S, et al. The first and second waves of the COVID-19 pandemic in Africa: a cross-sectional study. Lancet. 2021;397(10281):1265-1275.

67. Khanna RC, Cicinelli MV, Gilbert SS, Honavar SG, Murthy GV. COVID-19 pandemic: lessons learned and future directions. Indian J Ophthalmol. 2020;68(5):703-710. doi:10.4103/ijo.IJO_843_20

68. Stiles-Shields C, Plevinsky JM, Psihogios AM, Holmbeck GN. Considerations and future directions for conducting clinical research with pediatric populations during the COVID-19 pandemic. J Pediatr Psychol. 2020;45(7):720-724. doi:10.1093/jpepsy/jsaa055

69. AL-Hashimi M, Hamdan A. Artificial Intelligence and Coronavirus COVID-19: Applications, Impact and Future Implications. In: Alareeni B, Hamdan A, Elgedawy I, editors. The Importance of New Technologies and Entrepreneurship in Business Development: In the Context of Economic Diversity in Developing Countries. Springer International Publishing:2021;194:830. 


\section{Publish your work in this journal}

The Journal of Multidisciplinary Healthcare is an international, peerreviewed open-access journal that aims to represent and publish research in healthcare areas delivered by practitioners of different disciplines. This includes studies and reviews conducted by multidisciplinary teams as well as research which evaluates the results or conduct of such teams or healthcare processes in general. The journal covers a very wide range of areas and welcomes submissions from practitioners at all levels, from all over the world. The manuscrip management system is completely online and includes a very quick and fair peer-review system. Visit http://www.dovepress.com/testimonials. php to read real quotes from published authors. 